\title{
A Relação entre o Regulamento de Uso das Indicações Geográficas e o Conhecimento Tradicional: o caso do guaraná envolvendo os territórios de Maués e da Terra Indígena Andirá-Marau
}

\author{
The Relationship between Regulation Governing Use of Geographical \\ Indications and Traditional Knowledge: the case of guarana involving \\ the territories of Maués and of Indigenous Land Andirá-Marau
}

\author{
Igor Schumann Seabra Martins ${ }^{1}$ \\ Alexandre Guimarães Vasconcellos ${ }^{1}$ \\ ${ }^{1}$ Instituto Nacional da Propriedade Industrial, Rio de Janeiro, RJ, Brasil
}

\begin{abstract}
Resumo
Neste artigo serão analisados os casos relacionados à indicação de procedência "Maués" e ao pedido de registro da denominação de origem "Terra Indígena Andirá-Marau", ambas para guaraná, e discute-se o papel estratégico do regulamento de uso da indicação geográfica na preservação das práticas produtivas e tradições da coletividade. Utilizou-se pesquisa documental envolvendo os processos administrativos dessas indicações geográficas no INPI. Verificou-se que o regulamento de uso é estratégico para a coletividade que utiliza a indicação geográfica, pois tem relação direta com a identidade e tipicidade do produto, valorizando suas principais características e a estreita ligação com a origem geográfica. No caso da indicação de procedência "Maués", o Consórcio dos Produtores Sateré-Mawé verificou que o regulamento de uso não teria serventia especial para preservar e valorizar as formas de produção tradicional de sua coletividade, principalmente os métodos de produção agroflorestal do guaraná, o que motivou um pedido próprio de registro de denominação de origem.
\end{abstract}

Palavras-chave: Indicação Geográfica. Conhecimento Tradicional. Guaraná.

\begin{abstract}
The cases "Maués" indication of source and "Andirá-Marau" appellation of origin application related to guarana were analyzed regarding the strategic role of geographical indication regulation governing use in the preservation of productive practices and traditions of the collectivity. Documentary research involving the administrative processes at INPI of these geographical indications was performed. Regulation governing use showed strategic for the collectivity that uses the geographical indication, since it has a direct relation with product identity and typicity, valuing its main characteristics and the close connection with the geographic origin. In the case of "Maués" indication of source, the Sateré-Mawé Producers Consortium verified that regulation governing use would not be adequate in preserving and valuing the traditional forms of production of its collectivity, mainly the agroforestry methods of guaraná production, which motivated an own application of appellation of origin.
\end{abstract}

Keywords: Geographic Indication. Traditional Knowledge. Guaraná.

Área Tecnológica: Alimentos. Produtos Regionais. Indicação Geográfica. 


\section{Introdução}

As indicações geográficas (IGs) são signos de uso coletivos utilizados para distinguir produtos ou serviços peculiares devido à sua origem geográfica (NIEDERLE; MASCARENHAS; WILKINSON, 2017). O regulamento de uso do nome geográfico, ou, como atualmente denominado, "caderno de especificações técnicas" ${ }^{1}$ é um documento obrigatório para o reconhecimento da indicação geográfica e que, em geral, caracteriza os produtos ou serviços originários da região, assim como as respectivas cadeias produtivas (INPI, 2019a). Por estarem fortemente vinculadas a uma localidade, as atividades ali desenvolvidas frequentemente envolvem práticas próprias das comunidades da região (VALENTE; PEREZ; FERNANDES, 2013), inclusive conhecimentos tradicionais (FÁVERO, 2015). Tendo em vista que o termo "regulamento de uso" era o oficialmente adotado pela normativa em vigor à época da concessão do registro da IG "Maués", ele será utilizado ao longo deste trabalho para maior fidelidade ao trâmite processual e ao período histórico em questão.

\subsection{Conhecimentos Tradicionais}

Os conhecimentos tradicionais estão incluídos na noção de patrimônio imaterial, que, juntamente com o patrimônio material, compõem o patrimônio cultural brasileiro. O Instituto do Patrimônio Histórico e Artístico Nacional (IPHAN) é a autarquia federal vinculada ao Ministério da Cidadania responsável pela preservação e promoção dos bens culturais nacionais, assegurando sua permanência para o usufruto dos brasileiros, incluindo as gerações futuras (BELAS, 2007; CERDAN, 2013; IPHAN, 2019a).

De acordo com Souza e Locatelli (2015) e com o IPHAN (2019b), o conhecimento tradicional pode ser definido como o conjunto de saberes de comunidades tradicionais e de povos indígenas adquiridos com a vivência junto à natureza e a observação e experimentação de procedimentos e resultados. Tais conhecimentos se originaram da necessidade de adaptação $e$ sobrevivência ao ambiente, dos saberes dos antepassados e da troca de tais saberes com outros povos e comunidades, sendo transmitidos ao longo das gerações.

A terminologia "conhecimento tradicional" não se deve à sua antiguidade. Trata-se de um conjunto dinâmico de conhecimentos desenvolvidos, sustentados e transmitidos com o decorrer dos anos dentro de uma comunidade, frequentemente compondo sua identidade cultural ou espiritual. Devido à sua natureza dinâmica, o conhecimento tradicional não é protegido facilmente pelo sistema atual de propriedade intelectual, que caracteristicamente concede, temporariamente, direito de uso exclusivo de obras originais e novas invenções de pessoas ou empresas (SANTILLI, 2007; OMPI, 2016).

Os conhecimentos tradicionais são práticas extremamente importantes para a vida dos povos e das comunidades, fazendo parte do seu modo de vida e do cotidiano, mesmo quando detidos por apenas um de seus membros. São práticas utilizadas nas mais diferentes atividades, como na agricultura, medicina, caça, pesca, rituais religiosos e cuidados pessoais, estando diretamente ligadas aos povos indígenas e às comunidades quilombolas, ribeirinhas, caiçaras,

10 termo "regulamento de uso" foi oficializado pelo art. 6, III, da Instrução Normativa (IN) do INPI n. 25/2013, de 21 de agosto de 2013, mas foi alterado para "caderno de especificações técnicas" por força do art. 7º II, da IN n. 95/2018 de 28 de dezembro de 2018, que entrou em vigor em meados de março de 2019, revogando a IN n. 25/2013 (INPI, 2013; 2019b). 
parteiras, curandeiros, benzedeiras, entre outras (SANTILLI, 2007; SOUZA, LOCATELLI, 2015; IPHAN, 2019b).

Se o conhecimento tradicional estiver relacionado aos seres vivos, incluindo substâncias oriundas do metabolismo desses, é chamado de conhecimento tradicional associado ao patrimônio genético (BRASIL, 2015). Estão incluídos nesse ramo os conhecimentos associados ao uso de plantas e de animais, suas particularidades e potencialidades para diversos fins. Tais conhecimentos podem ser importantes para o desenvolvimento de pesquisas relacionadas à agricultura, pecuária e à produção de medicamentos e cosméticos (GARCÉS, 2007; SANTILLI, 2007; IPHAN, 2019b).

\subsection{Indicações Geográficas}

A Indicação Geográfica (IG) é um ativo de propriedade industrial utilizado para identificar a origem de produtos ou serviços quando o local tenha se tornado conhecido ou quando determinada característica ou qualidade do produto ou do serviço seja decorrente da sua origem geográfica (INPI, 2019a).

O conceito de IG surgiu há muito tempo e foi se desenvolvendo naturalmente ao longo dos anos, quando produtores, comerciantes e consumidores perceberam que alguns produtos possuíam qualidades peculiares decorrentes de sua origem geográfica. Tais produtos passaram a ser denominados com o nome geográfico de procedência, surgindo, como exemplo, os vinhos de Bordeaux e o queijo Roquefort (VALENTE et al., 2012; CERDAN, 2013).

De acordo com o artigo 176 da Lei n. 9.297, de 14 de maio de 1996, a Lei de Propriedade Industrial (LPI), constituem indicação geográfica a Indicação de Procedência (IP) ou a Denominação de Origem (DO). O artigo 177 da LPI dispõe que IP é o "[...] nome geográfico de país, cidade, região ou localidade de seu território, que se tenha tornado conhecido como centro de extração, produção ou fabricação de determinado produto ou de prestação de determinado serviço" (BRASIL, 1996). Por outro lado, conforme prevê o artigo 178 da LPI, "[...] considera-se denominação de origem o nome geográfico de país, cidade, região ou localidade de seu território, que designe produto ou serviço cujas qualidades ou características se devam exclusiva ou essencialmente ao meio geográfico, incluídos fatores naturais e humanos" (BRASIL, 1996). Em 20 de março de 2020 estavam registradas no país 76 IGs, sendo 55 IPs, todas nacionais, e 21 DOs, das quais 12 são nacionais e nove são estrangeiras (INPI, 2019a).

Fica claro que, como sugerido pelo próprio nome, a IG está intimamente relacionada com o local onde determinado produto é produzido ou serviço é prestado, estabelecendo uma conexão que pode trazer agregação de valor para eles e propiciar o desenvolvimento da própria região relacionada (VALENTE et al., 2012; CERDAN, 2013; SOUZA; LOCATELLI, 2015). Tal desenvolvimento pode advir da geração de renda obtida com o comércio de produtos e prestação de serviços de maior valor agregado, da geração de empregos, da mobilização e associação da população local, da atração do turismo e do aumento e melhoria da infraestrutura básica, a última sendo potencializada pelo próprio desenvolvimento local. A formulação de políticas públicas e privadas envolvendo as indicações geográficas é fundamental para o sucesso dessas políticas (VALENTE et al., 2012; CERDAN, 2013).

No caso específico do guaraná de Maués, esforços para agregar-lhe valor são cruciais para a diversificação de mercados e a redução de gargalos na geração de renda para as famílias 
produtoras (SILVA et al., 2018). Para tal, deve ser destacada a importância da aliança entre desenvolvimento tecnológico e biodiversidade amazônica para a geração de riqueza na região considerando sua vocação natural. Dessa forma, será possível incrementar inovações no setor de bioprodutos, visto que, atualmente, a maior concentração de invenções ainda se situa no setor de eletroeletrônicos (FRICKMANN; VASCONCELLOS, 2013). Nesse sentido, a utilização do sinal da indicação geográfica representa uma importante oportunidade para a valorização do guaraná, desde que devidamente organizada e estruturada a governança local (SILVA et al., 2018; SOUZA, 2016).

Do ponto de vista da concorrência, o registro da IG dá aos produtores da região que respeitarem as condições e regras do regulamento de uso/caderno de especificações técnicas o direito de uso exclusivo desse sinal. Assim, pode ser combatido de forma enérgica o uso indevido da IG e a pirataria do produto assinalado. Para os antigos agricultores de guaraná de Maués, seria uma vitória, dado que eles zelavam pela sua produção, mas nada puderam fazer quando milhares de mudas foram exportadas pelo porto de Maués e, anos depois, foram utilizadas para abastecer o mercado nacional, adotando-se, em muitos casos, o nome de Maués, para garantir preço e mercado (SOUZA, 2016).

No entanto, mesmo antes do registro da IG, já é possível visualizar benefícios para a comunidade local. Requerer o registro de uma IG pressupõe uma organização dos produtores para a discussão dos processos, estratégias e controles que nortearão o uso do sinal e a criação ou escolha de uma entidade (o substituto processual) para representar os produtores e depositar o pedido no Instituto Nacional da Propriedade Industrial (INPI). Em outras palavras, os preparativos para a indicação geográfica promovem o associativismo, a troca de informações e a articulação dos grupos produtores.

Para os produtores de Maués, em particular, essas possibilidades seriam importantes para contornar os gargalos que permeiam a cadeia de valor no território, como a falta de representatividade das organizações socioprodutivas (há poucas associações e cooperativas atuantes na cadeia), a desarticulação dos grupos produtivos, a baixa eficiência produtiva, os altos custos de produção, a logística e a assimetria de informações entre atores e elos participantes da cadeia (SILVA et al., 2018).

A título de informação, para reivindicar o registro da IG, o substituto processual deve apresentar os documentos estabelecidos no artigo $7^{\circ}$ da Instrução Normativa (IN) do INPI n. 95/2018 de 28 de dezembro de 2018 (INPI, 2019a; 2019b). Cabe ressaltar que o depósito e o exame técnico do pedido de registro da IP "Maués" foram realizados sob a vigência da IN n. 25/2013, de 21 de agosto de 2013, já revogada pela IN n. 95/2018, vigente a partir de meados de março de 2019.

\subsection{O Regulamento de Uso do Nome Geográfico}

O regulamento de uso do nome geográfico era um dos documentos obrigatórios que o substituto processual deveria apresentar ao INPI ao solicitar o reconhecimento de uma IG. Tal imposição encontrava-se, de forma objetiva, no artigo 6 , inc. III da IN revogada n. 25/2013, sem, no entanto, indicar quais informações o respectivo documento deveria apresentar. Atualmente, a IN n. 95/2018, em seu artigo $7^{\circ}$, inciso II, denomina o antigo "regulamento de uso" 
como "caderno de especificações técnicas" e estabelece expressamente seu conteúdo obrigatório das alíneas "a" a "h" do mesmo inciso² (INPI, 2019b).

No entanto, ponderando sobre o conteúdo dos regulamentos de uso apresentados sob a vigência da IN n. 25/2013, é possível apontar que o documento continha as regras aprovadas, geralmente em assembleia, pela coletividade (produtores ou prestadores do serviço) detentora dos direitos sobre a IG. Tais regras comumente retratam a tipicidade do produto e as melhores práticas da cadeia produtiva, o que possibilita a valorização de seus atributos principais e a preservação do vínculo com a região de origem. Segundo Valente, Perez e Fernandes (2013), o fator mais considerado na definição das regras do regulamento de uso é a tradição produtiva da região, o saber-fazer local, ainda que, eventualmente, haja introdução de inovações tecnológicas no processo produtivo.

A elaboração do regulamento de uso/caderno de especificações técnicas é um processo complexo, uma vez que cada regra estabelecida pode implicar na exclusão de produtores ou prestadores de serviços, tanto por critérios geográficos, quanto por exigências técnicas, que podem acarretar em custos e necessidade de investimentos adicionais por parte dos interessados na utilização da IG (VALENTE; PEREZ; FERNANDES, 2013).

Ainda que seja um processo demorado e dispendioso, a elaboração dos regulamentos de uso/cadernos de especificações técnicas tem sido facilitada pela orientação de entidades governamentais parceiras, incluindo instituições de ensino e pesquisa, organizações não governamentais (ONGs), órgãos estaduais e o próprio INPI (VALENTE; PEREZ; FERNANDES, 2013). Tais parcerias são extremamente benéficas, pois, estando o regulamento de uso bem estruturado e claro, pode tornar-se uma ferramenta importante para a preservação das tradições da coletividade e para o fortalecimento da própria IG.

É importante ressaltar que o INPI disponibiliza gratuitamente em seu sítio eletrônico, a saber, http://www.inpi.gov.br/menu-servicos/indicacao-geografica/regulamento-de-uso-das-indicacoes-geograficas, o regulamento de uso do nome geográfico/caderno de especificações técnicas de cada uma das 76 indicações geográficas registradas até 20 de março de 2020.

\subsection{O Regulamento de Uso e os Conhecimentos Tradicionais}

Tendo em vista que o regulamento de uso/caderno de especificações técnicas das IGs, em geral, contém informações relacionadas à tipicidade do produto assinalado pela IG e às práticas da respectiva cadeia produtiva, comumente está inserida, como consequência, a descrição de conhecimentos tradicionais próprios das comunidades produtoras (INPI, 2019a; 2019b).

No entanto, é imperativo dizer que, partindo-se da leitura dos artigos 177 e 178 da LPI, a IG é o nome geográfico, nos termos que se seguem:

Art. 177 Considera-se indicação de procedência o nome geográfico de país, cidade, região ou localidade de seu território [...]

\footnotetext{
${ }^{2} \mathrm{O}$ caderno de especificações técnicas deve conter: a) o nome geográfico a ser protegido, acrescido ou não do nome do produto ou serviço; b) a descrição do produto ou serviço objeto da Indicação Geográfica; c) a delimitação da área geográfica conforme instrumento oficial; d) a descrição do processo de extração, produção ou fabricação do produto ou de prestação do serviço, pelo qual o nome geográfico se tornou conhecido, no caso de ser uma IP; e) a descrição das qualidades ou características do produto ou serviços que se devam exclusiva ou essencialmente ao meio geográfico, incluindo fatores naturais e humanos, e seu processo de obtenção ou prestação, no caso de ser uma DO; f) a descrição do mecanismo de controle sobre os produtores ou prestadores de serviços que tenham o direito ao uso da Indicação Geográfica, bem como sobre o produto ou serviço por ela distinguido; g) as condições e proibições de uso da Indicação Geográfica; e h) eventuais sanções aplicáveis à infringência do disposto na alínea anterior (INPI, 2019b).
} 
Art. 178 Considera-se denominação de origem o nome geográfico de país, cidade, região ou localidade de seu território [...]. (BRASIL, 1996)

Dessa maneira, fica claro que a proteção da IG, nos termos da legislação brasileira, recai tão somente sobre o nome geográfico ${ }^{3}$. Ou seja, o direito gerado com o reconhecimento de uma IG pode ser traduzido na exclusividade do uso do nome geográfico pelos produtores, não protegendo os conhecimentos tradicionais das comunidades inseridas nos limites de sua área geográfica.

Ademais, conforme apontam Souza e Locatelli (2015), os conhecimentos tradicionais nem sempre estão relacionados a uma área geográfica determinada, não obstante a importância do vínculo com o meio natural. Segundo as autoras, tais saberes transcendem o meio geográfico de origem, e, ainda que se possam delimitar várias regiões, por vezes, não são passíveis de delimitação geográfica, eis que perpassado para várias gerações que não mantêm, necessariamente, um vínculo com uma ou mais localidades determináveis.

No entanto, o conhecimento tradicional, normalmente mantido pela tradição oral de comunicação de vivências e observações, pode beneficiar-se do registro sistematizado das informações para sua preservação e perpetuação. Em outras palavras, "[...] cabe capsular em alguma forma estática (registro) como meio de conservar a memória, proporcionar a continuidade da cultura de uma sociedade e protegê-la do sistema globalizado de cultura" (BERTOLDI; SPOSATO, 2012, p. 82). Dessa maneira, a memória coletiva de tais comunidades, se codificada em algum suporte material, como o regulamento de uso de uma IG, estaria protegida de eventual extinção ou interferência externa. Neste contexto, a documentação dos conhecimentos tradicionais pode ser fator fundamental para sua preservação ao longo do tempo.

Em acréscimo, conforme indicado por Niederle, Mascarenhas e Wilkinson (2017), a IG pode ser fator de agregação de valor ao produto por ela assinalado, e, se bem gerida, facilitar o desenvolvimento econômico da respectiva localidade. Assim sendo, na medida em que a IG estimula uma estruturação em setores e uma remuneração supostamente garantida, surgem novas perspectivas em termos de emprego, atraindo para a atividade novos produtores, incluindo os das gerações mais novas, que poderão se aproveitar da tradicionalidade historicamente construída e do maior conhecimento de terceiros sobre o respectivo território (CERDAN, 2013). Com posição similar, Fernandes e Pedreira (2013, p. 228) afirmam:

Entende-se o reconhecimento de uma indicação geográfica, seja de produtos ou serviços, como uma forma de preservação, uma garantia para assegurar determinada reputação $e$, assim, permitir a reprodutibilidade dos processos produtivos e do saber-fazer, possibilitando a sustentabilidade econômica dos produtores envolvidos e assegurando a sustentabilidade de arranjos produtivos locais.

Segundo Fernandes e Pedreira (2013), a atratividade gerada sobre as novas gerações se torna fator determinante para a preservação e continuidade dos conhecimentos e práticas próprios da respectiva coletividade. É possível dizer, portanto, que a IG, se bem-sucedida, pode contribuir, ainda que indiretamente, para resguardar os conhecimentos tradicionais de determinada comunidade.

\footnotetext{
${ }^{3}$ Como extensão da proteção, ressalta-se o disposto no art. 179 da LPI: "A proteção estender-se-á à representação gráfica ou figurativa da indicação geográfica, bem como à representação geográfica de país, cidade, região ou localidade de seu território cujo nome seja indicação geográfica” (BRASIL, 1996).
} 
Em sentido contrário, Niederle, Mascarenhas e Wilkinson (2017) alegam que a inovação nas práticas produtivas favorecidas pela IG, muitas vezes com tecnologia de origem externa aos seus limites territoriais poderia pôr em risco o vínculo histórico entre os produtos ou serviços e o patrimônio cultural e ecológico da região.

Algumas das IGs registradas junto ao INPI incluem, nos respectivos regulamentos de uso, conhecimentos tradicionais próprios das comunidades inseridas na área delimitada. É possível citar as IPs "Goiabeiras", para panelas de barro; "Canastra", para queijos; e, principalmente, "Maués", para guaraná, incluídas, respectivamente nos estados do Espírito Santo, Minas Gerais e Amazonas. A última se destaca devido ao trâmite processual que inclui a manifestação de terceiros envolvendo práticas de conhecimentos tradicionais da região.

Este trabalho tem por objetivo analisar os casos relacionados à IP "Maués" e ao pedido de DO "Terra Indígena Andirá-Marau" relacionados ao guaraná e discutir o papel estratégico do regulamento de uso da IG na preservação das práticas produtivas e tradições da coletividade.

\section{Metodologia}

Este trabalho utiliza-se de pesquisa documental. Conforme afirma Gil (2002, p. 45):

A pesquisa documental assemelha-se muito à pesquisa bibliográfica. A diferença essencial entre ambas está na natureza das fontes. Enquanto a pesquisa bibliográfica se utiliza fundamentalmente das contribuições dos diversos autores sobre determinado assunto, a pesquisa documental vale-se de materiais que não recebem ainda um tratamento analítico, ou que ainda podem ser reelaborados de acordo com os objetos da pesquisa.

Nesse contexto, debruça-se aqui sobre a análise de documentos públicos de primeira mão, quais sejam, os documentos de fonte primária existentes no INPI relacionados: 1) aos pedidos de registro de IG, na modalidade IP, para o nome geográfico "Maués", incluindo seu regulamento de uso; 2) ao registro da DO "Terra Indígena Andirá Marau" para guaraná em pó, pães de guaraná (bastão) e casquilho de guaraná pelo Consórcio dos Produtores Sateré-Mawé, incluindo seu regulamento de uso; e 3) às petições interpostas durante o transcorrer dos processos administrativos.

Os processos administrativos referentes ao pedido de registro da IP "Maués", identificado pelo número BR402015000001-0, e ao pedido de registro da DO “Terra Indígena Andirá-Marau", de número BR412016000005-2, assim como as petições interpostas em seu curso, nos termos da Lei n. 12.527, de 18 de novembro de 2011, a Lei de Acesso à Informação, podem ser acessados integralmente pelo público mediante vista ao processo físico ou on-line (quando disponível) ou por meio de petição específica apresentada ao INPI, de nome "cópia reprográfica simples", ou meramente "pedido de fotocópia". Tal petição é identificada pelo código 824-2 e pode ser obtida no endereço eletrônico do INPI, mais precisamente em: http://www.inpi.gov. br/arquivos/tabela-nova-ig.pdf.

As petições de "manifestação de terceiros", "contestação da requerente" "documentos complementares para a contestação à manifestação de terceiros" estão identificadas, respectivamente, pelos números 020160003265, 020170001472 e 020170003570 e podem ser acessadas, individualmente, da mesma forma relatada acima para os processos administrativos. 


\section{Resultados e Discussão}

Os resultados e a discussão deste trabalho têm como base os trâmites burocráticos dos pedidos de registro da IP Maués e da DO Terra Indígena Andirá-Marau, depositados no INPI, suas principais fases e os atores por elas responsáveis encontram-se descritos a seguir.

\subsection{Caso Prático: a indicação de procedência "Maués"}

Em 6 de fevereiro de 2015, a Associação dos Produtores de Guaraná da Indicação Geográfica de Maués, atuando como substituto processual, depositou no INPI pedido de registro de IG, na modalidade IP, para o nome geográfico "Maués". O produto assinalado foi descrito como "Guaraná da espécie Paulinia cupana var. sorbilis" (INPI, 2015).

O município de Maués caracteriza-se como uma região intrinsecamente ligada à cultura do guaraná. A partir dos dados históricos, socioeconômicos e culturais, Maués possui condições edafoclimáticas propícias, pesquisa agrícola, cultura da população, tradição das famílias produtoras, tecnologia de manejo e beneficiamento secular. Devido a tais particularidades, o guaraná procedente de Maués se tornou conhecido por sua originalidade e qualidade (INPI, 2015).

A delimitação geográfica da IP coincidia com os limites político-administrativos do município de Maués (Mapa 1) e o regulamento de uso continha determinações sobre: a área de produção; a cultivar recomendada para a produção de guaraná; os sistemas de produção, de colheita $e$ de beneficiamento; os requisitos e procedimentos para a utilização da representação gráfica; $e$ a atuação do Conselho Regulador (INPI, 2015).

Mapa 1 - Mapa da localização, situação e confrontes dos limites territoriais da IP "Maués"

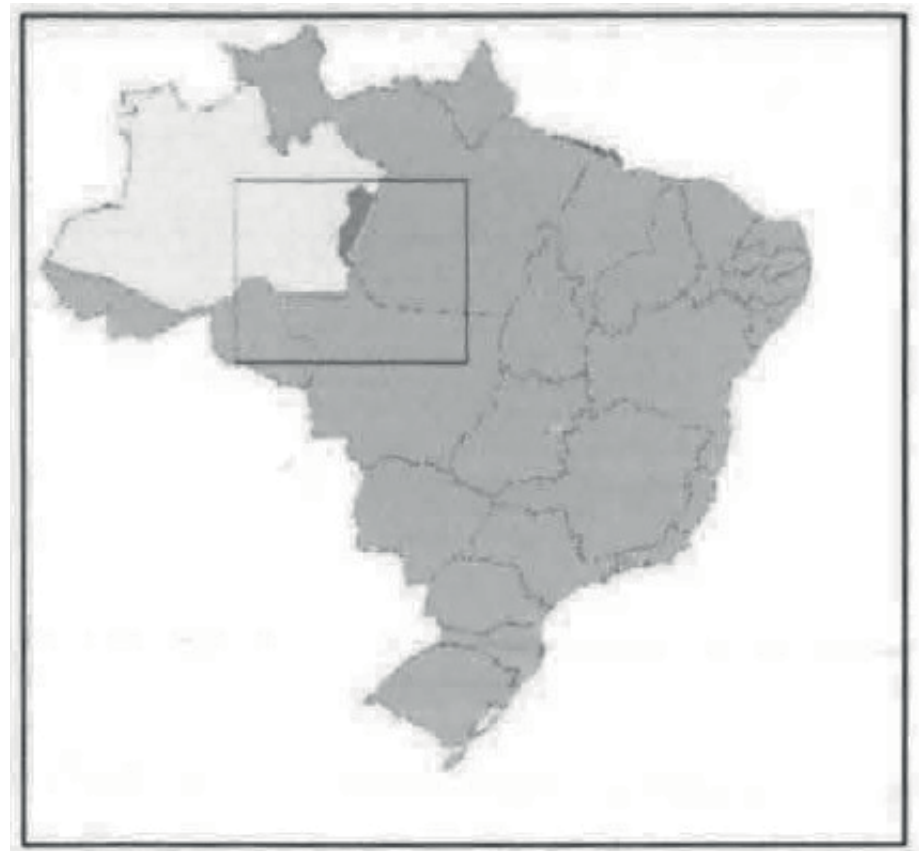

Nota: Extraído de INPI (2015), mas elaborado pelo geólogo Andrew Jackson Muller Silva - CREA 12.131-D/AM.

Fonte: INPI (2015)

Inicialmente, o respectivo processo administrativo sofreu exigências formais, que foram publicadas na RPI 2349, de 12 de janeiro de 2016, e prontamente cumpridas pela associação 
em 19 de março de 2016. Sanando as conformidades apontadas pelo examinador, o pedido foi publicado para manifestação (oposição) de terceiros na RPI 2359, de 22 de março de 2016 (INPI, 2015).

\subsection{Manifestação de Terceiros}

Em 17 de maio de 2016 foi protocolizada, por via postal, petição contendo manifestação de terceiros em nome do Consórcio dos Produtores Sateré-Mawé (CSPM). O Consórcio foi apresentado como uma entidade autônoma auxiliar do Conselho Geral da Tribo Sateré-Mawé (CGTSM). O CPSM seria responsável por organizar o usufruto coletivo dos recursos da biodiversidade da Terra Indígena Andirá-Marau, demarcada e homologada, que se situa entre os estados do Amazonas e Pará. A demarcação dessa terra indígena abrange cinco municípios: Itaituba e Aveiro, no estado do Pará, Barreirinha, Parintins e Maués no estado do Amazonas (INPI, 2015).

A manifestante, CSPM, alega por meio da carta do CGTSM ao chefe de gabinete do Instituto de Desenvolvimento Agropecuário e Florestal Sustentável do Estado do Amazonas - (IDAM), haver uma tentativa de desvirtuação do guaraná produzido pela tribo indígena por meio da introdução de mudas clonadas de guaraná e de técnicas de cultivo nocivas às práticas tradicionais na Terra Indígena Andirá-Marau. Tais práticas, segundo especialistas citados na carta, descaracterizariam o produto tradicional produzido pela tribo indígena e impactariam seriamente o modo de vida dos ocupantes da Reserva Indígena delimitada (INPI, 2015).

O CSPM alega conflito entre os seus interesses, o direito de uso da terra indígena e as informações constantes no pedido de registro da IP "Maués". Segundo a manifestante, o regulamento de uso apresentado pela requerente é ofensivo, pois faz alusão a uma parte imaginariamente separada da comunidade indígena em que ele seria aplicado e promovido, incentivando práticas como a utilização de clones e defensivos agrícolas, o que afronta os valores religiosos, éticos e conviviais que fundamentam a identidade étnica do povo indígena Sateré-Mawé (INPI, 2015). Essa problemática também foi apontada por Souza (2016, p. 21), que afirma:

Porém, há um viés que deve ser evidenciado nesse projeto. $\mathrm{O}$ fato de não incorporar os membros da etnia sateré-mawé já apresenta anormalidade. Analisando a legislação que regulamenta esse projeto, verifica-se que a mesma vai em direção da anulação das práticas tradicionais, invalidando-as e impondo praticamente o manejo tecnificado da cultura, ao deixar claro que se deve dar preferências para as mudas clonadas (estaquia) $e$ uso da adubação química, uso de defensivos sem mencionar que o agricultor pode utilizar de tecnologias mais sustentáveis e assim fazer parte desse projeto. Ao anular as práticas tradicionais, esse selo exerce forte pressão para a superação das antigas práticas.

Nesse sentido, a definição no regulamento de uso de sistemas de produção adequados às boas práticas agrícolas e de fabricação estabeleceram padrões para superar problemas técnicos e gargalos na cadeia de valor do guaraná. No entanto, tais boas práticas podem anular o saber fazer e alguns conhecimentos tradicionais da etnia indígena Sateré-Mawé, o que poderia incentivar o seu abandono ao longo do tempo (SOUZA, 2016). Assim, estaria ameaçado o vínculo histórico entre o produto e o patrimônio cultural e ecológico da região, tal como apontado por Niederle, Mascarenhas e Wilkinson (2017). 
Ainda, o CSPM questiona o produto indicado, a saber, guaraná da espécie Paullinia cupana var. sorbilis. Alega não ser, tal produto, comercializado como espécie botânica, mas sim em distintas formas de beneficiamento de suas sementes. Logo, ocorre uma lacuna na identificação dos produtos assinalados pela IP Maués, os quais são apenas mencionados indiretamente. Portanto, haveria a necessidade de se apontar objetivamente que os produtos assinalados são as sementes torradas de guaraná e o guaraná em pó (INPI, 2015).

De forma geral, em toda a petição de manifestação, as lideranças Sateré-Mawé reafirmam sua autonomia cultural, social, política e econômica, expressando veemente e inequívoca oposição à inclusão da Terra Indígena Andirá-Marau na delimitação da área de abrangência da IP Maués. Alegam ainda que a inclusão da terra indígena no território da IP foi realizada sem consulta prévia à organização indígena (INPI, 2015).

A manifestante sugere três possibilidades de modificações:

1) Flexibilização do regulamento de uso, viabilizando a adoção de produções alternativas, como a produção orgânica e agroecológica.

2) Restrição da área delimitada para abranger apenas os locais onde estão efetivamente os produtores que concordam com a atual proposta.

3) Revisão da área delimitada para a IP Maués, excluindo completamente a área da Terra Indígena Andirá-Marau.

\subsection{Contestação da Requerente}

A contestação da requerente foi protocolizada por via postal, tempestivamente, em 17 de abril de 2017. Como defesa, a associação apresentou, entre outros, o documento intitulado Descrição e Característica do Produto Maués para Guaraná, onde constam: histórico da guaranicultura no município de Maués, caracterização social e edafoclimática de Maués, e parecer técnico agronômico sobre a cultura do guaraná e seus produtos derivados (INPI, 2015).

Segundo o estudo, a economia do município de Maués se baseia principalmente na produção local de guaraná, sendo conhecido como a terra do guaraná. O documento reconhece a importância do povo indígena ao indicar que os índios Sateré-Mawé domesticaram a variedade vegetal selvagem e criaram o processo de beneficiamento do guaraná. Ressalta, ainda, que os conhecimentos desenvolvidos pelos Sateré-Mawé, referentes ao cultivo do guaraná, foram adaptados pelos moradores de Maués ao longo dos anos, tendo sido a atividade impulsionada, sobretudo, pela chegada de famílias vindas do nordeste do Brasil, Itália e Japão (INPI, 2015).

O parecer técnico agronômico justifica a utilização de clones de sementes guaraná pela incidência de antracnose (doença causada por um fungo). Tais clones, desenvolvidos pela Embrapa Amazônia seriam resistentes a doenças e pragas, além de mais produtivos do que as variedades originais (INPI, 2015).

No entanto, como medida mais importante em toda a petição de contestação, a requerente apresenta, por meio do documento intitulado Memorial Descritivo da área Delimitada da Indicação Geográfica de Maués - IP - Município de Maués - Amazonas, nova delimitação da área geográfica, excluindo, de forma clara, a área da Terra Indígena Andirá-Marau, localizada na porção nordeste do município (Mapa 3). O documento é assinado por representante do Instituto de 
Desenvolvimento Agropecuário e Florestal do Estado do Amazonas (IDAM) e por representante da EMBRAPA (INPI, 2015).

Mapa 3 - Área da IP "Maués" após a exclusão da Terra Indígena Andirá-Marau, representada na escala $1: 1: 000.000$

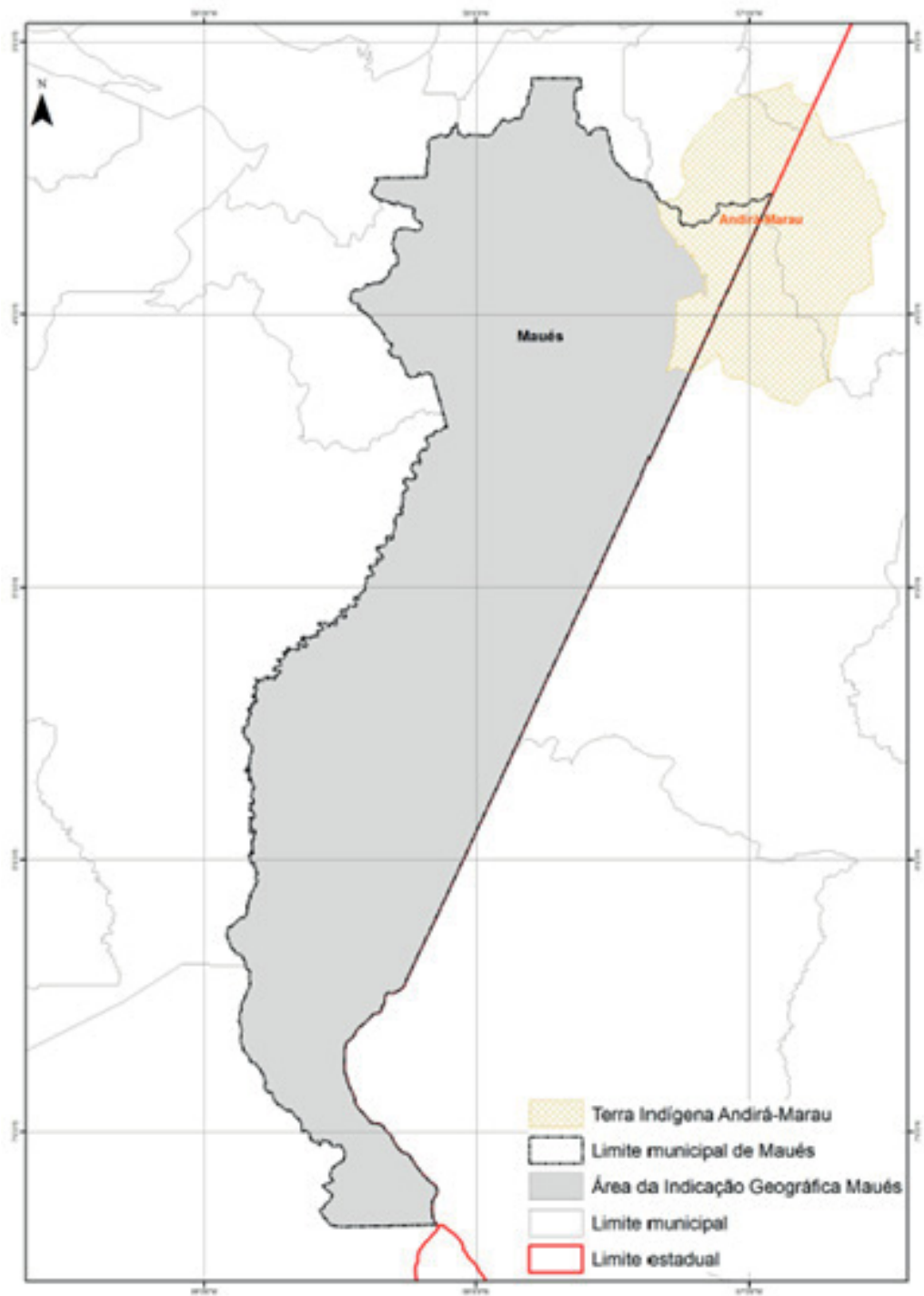

Nota: Extraído de INPI (2015), mas elaborado pelo Instituto Brasileiro de Geográfica e Estatística (IBGE).

Fonte: INPI (2015)

Em 6 de outubro de 2017 foi protocolada nova petição, destinada a complementar a contestação à manifestação de terceiros e contendo argumentos e considerações em defesa do reconhecimento da IP Maués (INPI, 2015).

A requerente argumenta que, diferentemente do sistema de produção do guaraná utilizado pelos indígenas, as técnicas de cultivo e de processamento do guaraná utilizadas pelos agricultores familiares ou produtores rurais do município de Maués enfatizam a importância do produto com potencial econômico para desenvolver o município. Assim, foram introduzidas técnicas de cultivo com o uso de defensivos agrícolas, adubos químicos e mudas assexuadas, tais técnicas foram determinantes no estabelecimento das diferenças para com o sistema de produção tradicional utilizado pelos indígenas (INPI, 2015). 
Sobre a definição do produto assinalado, a requerente entende que o produto "guaraná" seria apropriado, pois Maués tornou-se conhecido como centro de extração do fruto guaraná (INPI, 2015).

A requerente conclui afirmando que as considerações elencadas, assim como as alterações propostas nos documentos apresentados na contestação, cumprem todos os requisitos de registro. Solicita, portanto, a concessão da IP "Maués" (INPI, 2015).

A concessão da IP "Maués" foi publicada na RPI 2454, de 16 de janeiro de 2018, sendo a primeira IG destinada a produto in natura no estado do Amazonas (INPI, 2019a).

Figura 1 - Representação da IP "Maués", conforme registrada no INPI

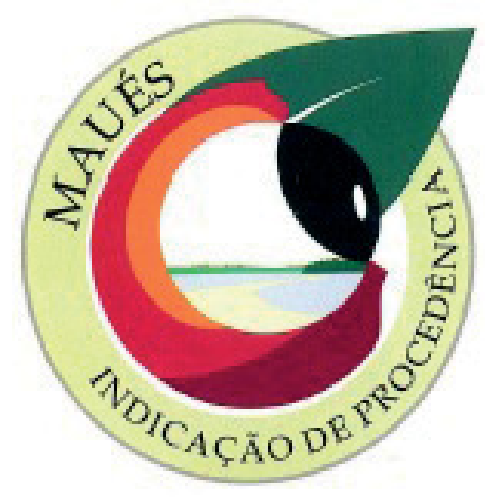

Fonte: INPI (2015; 2019a)

\subsection{A Denominação de Origem "Terra Indígena Andirá-Marau"}

Em 20 de outubro de 2016, o CPSM depositou no INPI pedido de reconhecimento da DO "Terra Indígena Andirá-Marau" para guaraná em pó, pães de guaraná (bastão) e casquilho de guaraná (INPI, 2016).

Figura 2 - Representação da DO "Terra Indígena Andirá-Marau", conforme solicitada no INPI

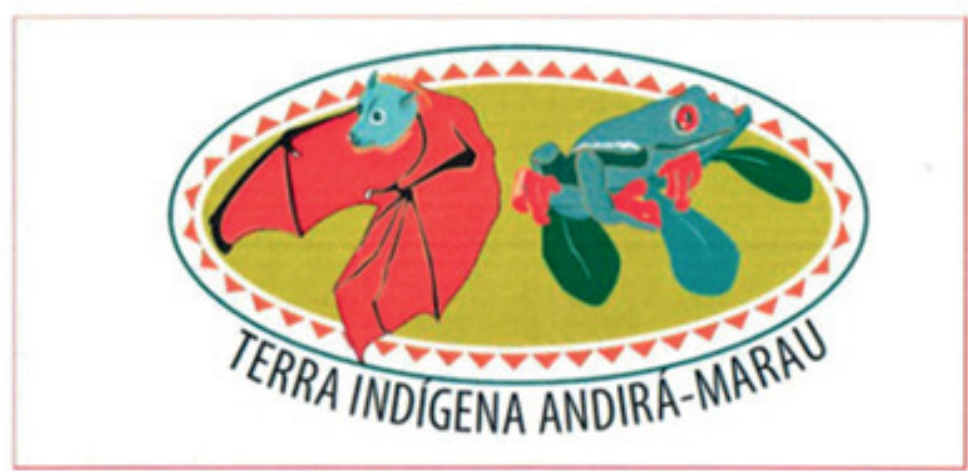

Fonte: INPI (2016; 2019a)

A delimitação geográfica da respectiva DO consiste na área demarcada pela Fundação Nacional do Índio (FUNAI) e por duas áreas adjacentes tradicionalmente ocupadas pela etnia Sateré-Mawé (INPI, 2016). 
Segundo a requerente do pedido, os guaranazais, na Terra Indígena Andirá-Marau, ocorrem de forma intercalada com árvores nativas, espontâneas ou introduzidas em épocas remotas ou recentes, via sistemas agroflorestais. O diferencial da região decorre da polinização das flores do guaranazeiro por abelhas nativas, prática essencial para a existência e evolução da espécie vegetal (INPI, 2016).

Em verificação do trâmite processual junto ao INPI realizada em 20 de março de 2020, já sob a vigência da IN n. 95/2018, o pedido de registro encontrava-se em fase de exame de mérito, cuja publicação para manifestação de terceiros se deu em 28 de maio de 2019. Vale destacar que não houve manifestação de terceiros ao fim dos 60 dias previstos no artigo 12 , § $2^{\circ}$ da IN n. 95/2018 (INPI, 2019a).

\section{Considerações Finais}

A IG é um ativo de propriedade industrial que, conforme a LPI, protege apenas o nome geográfico. No entanto, a indicação geográfica, se agregar valor ao produto propiciando a estruturação em setores, pode atrair o interesse das novas gerações e, consequentemente, favorecer a preservação e a continuidade dos conhecimentos tradicionais ligados aos produtos ou serviços por ela assinalados. Ademais, tais saberes, se devidamente descritos no regulamento de uso/caderno de especificações técnicas de uma IG, estariam protegidos de eventual extinção ou interferência externa.

Entre as diversas IGs reconhecidas pelo INPI merece destaque a IP "Maués", justamente pela apresentação de manifestação de terceiros envolvendo matéria que inclui conhecimentos tradicionais próprios de etnia indígena. Visando a contornar as alegações da manifestante (CSPM), foi alterada a delimitação da área da indicação geográfica, excluindo dessa área a Terra Indígena Andirá-Marau. Não havendo mais objeções, a IP "Maués" foi reconhecida em 16 de janeiro de 2018 (INPI, 2019a).

O regulamento de uso, ou como atualmente denominado "caderno de especificações técnicas", é um documento estratégico para a coletividade que utiliza a IG, pois tem relação direta com a identidade e tipicidade do produto, valorizando suas principais características e a estreita ligação com a origem geográfica. A manifestação feita pelo CPSM solicitando a flexibilização do regulamento de uso da IP Maués ou a revisão da sua área delimitada, excluindo completamente a área da Terra Indígena Andirá-Marau, aponta para o entendimento desta comunidade indígena sobre a importância do regulamento de uso. Tendo em vista que o referido consórcio constatou que os modos de produção dos Sateré-Mawé não estariam contemplados no referido documento, ficou claro que a IP Maués não teria serventia especial para preservar e valorizar as formas de produção tradicional de sua coletividade no que tange, em destaque, aos métodos de produção agroflorestal do guaraná. Ademais, a inclusão da terra indígena no limite territorial de uma IG cujo regulamento de uso institua práticas como a utilização de clones e defensivos agrícolas poderia ser uma afronta aos valores religiosos, éticos e conviviais que fundamentam a identidade étnica do povo indígena Sateré-Mawé, ou, em outras palavras, poderia ofender seus conhecimentos tradicionais consagrados ao longo dos anos.

O pedido de reconhecimento da DO "Terra Indígena Andirá-Marau” para guaraná em pó, pães de guaraná (bastão) e casquilho de guaraná pelo CPSM, com base na diferenciação da 
forma de produção associada a fortes aspectos do conhecimento tradicional vivenciado em sistemas agroflorestais, traz à tona importantes considerações para o desdobramento desse estudo. Primeiramente, acompanhando analiticamente se a peculiaridade da forma de produção tradicional do guaraná adotada pelo CPSM permite que tal produto detenha qualidades ou características que se devem exclusiva ou essencialmente ao meio geográfico, incluídos fatores naturais e humanos justificando, dessa forma, o reconhecimento da $\mathrm{DO}$. O segundo ponto de grande interesse para um futuro estudo de caso é analisar, caso a DO "Terra Indígena Andirá-Marau" seja reconhecida pelo INPI, se estas comunidades indígenas conseguirão criar um nicho de mercado próprio e diferenciado em termos de visibilidade junto aos consumidores, com consequente agregação de valor aos produtos. E, por fim, a análise mais importante, qual seja, a de verificar se essas comunidades indígenas conseguirão utilizar o reconhecimento da IG como um instrumento de apoio à preservação do seu saber-fazer ou, num contexto mais amplo, como elemento convergente para a preservação de suas tradições e cultura.

\section{Referências}

BELAS, C. A. O Conceito de Patrimônio Imaterial e a Prática dos Inventários Culturais. In: BARROS, B. S. et al. (org.). Proteção aos Conhecimentos das Sociedades Tradicionais. Pará: Museu Paraense Emílio Goeldi, Centro Universitário do Pará, 2007. p. 265-280.

BERTOLDI, M. R.; SPOSATO, K. B. Instrumentos de Proteção dos Conhecimentos Tradicionais Associados à Biodiversidade. Revista de Direitos Fundamentais e Democracia, Curitiba, [S.l.], v. 12, n. 12, p. 75-93, julho-dezembro de 2012.

BRASIL. Lei n. 9.279, de 14 de maio de 1996. Lei da Propriedade Industrial Diário Oficial [da] República Federativa do Brasil, Brasília, DF, 15 de maio de 1996. Disponível em: http://www. planalto.gov.br/ccivil_03/leis/L9279.htm. Acesso em: 28 jun. 2018.

BRASIL. Lei n. 13.123, de 20 de maio de 2015. Diário Oficial [da] República Federativa do Brasil, Brasília, DF, 20 de maio de 2015. Disponível em: http://www.planalto.gov.br/ccivil_03/_ ato2015-2018/2015/lei/113123.htm. Acesso em: 4 jul. 2018.

CERDAN, C. Indicações Geográficas e estratégias de desenvolvimento territorial. In: NIEDERLE, P. A. (org.). Indicações Geográficas: qualidade e origem nos mercados alimentares. Rio Grande do Sul: Editora UFRGS, 2013. p. 125-150.

FÁVERO, K. C. Indicações geográficas como instrumento de proteção dos conhecimentos tradicionais. In: VIEIRA, A. C. P.; BRUCH, K. L. (org.). Indicação Geográfica, Signos Coletivos e Desenvolvimento. São Paulo: IBPI. 2015. p. 131-149.

FERNANDES, L. R. R. M. V.; PEDREIRA, R. B. A Proteção no Brasil das Indicações Geográficas nacionais no período 1997-2011. In: NIEDERLE, P. A. (org.). Indicações Geográficas: qualidade e origem nos mercados alimentares. Rio Grande do Sul: Editora UFRGS, 2013. p. 227-243.

FRICKMANN, F. S. S.; VASCONCELLOS, A. G. Awakening the biodiversity potential trough ST\&I investiments in the sector of amazonian biotechlology. Journal of Technology Management \& Innovation, [S.I.], Special Issue ALTEC, v. 8, 2013.

GARCÉS, C. L. L. Proteção aos Conhecimentos das Sociedades Tradicionais: Tendências e Perspectivas. In: BARROS, B. S. et al. (org.). Proteção aos Conhecimentos das Sociedades Tradicionais. Pará: Museu Paraense Emílio Goeldi, Centro Universitário do Pará. 2007. p. 71-84. 
GIL, A. C. Como elaborar projetos de pesquisa. 4. ed. São Paulo: Atlas, 2002.

INPI - INSTITUTO NACIONAL DA PROPRIEDADE INDUSTRIAL. Guia básico de indicação geográfica, 2019a. Disponível em: http://www.inpi.gov.br/menu-servicos/indicacao-geografica/guiabasico-de-indicacao-geografica. Acesso em: 7 ago. 2019.

INPI - INSTITUTO NACIONAL DA PROPRIEDADE INDUSTRIAL. Instrução Normativa n. 25, de 21 de agosto de 2013. Revista da Propriedade Industrial. Rio de Janeiro, Seção I, n. 2.230, $1^{\circ}$ outubro 2013. Disponível em: http://revistas.inpi.gov.br/rpi/. Acesso em: 2 jul. 2018.

INPI - INSTITUTO NACIONAL DA PROPRIEDADE INDUSTRIAL. Instrução Normativa n. 95, de 28 de dezembro de 2018. Revista da Propriedade Industrial. Rio de Janeiro, Seção I, n. 2.504, 2 janeiro 2019b. Disponível em: http://revistas.inpi.gov.br/rpi/. Acesso em: 7 ago. 2019.

INPI - INSTITUTO NACIONAL DA PROPRIEDADE INDUSTRIAL. Processo Administrativo para o Reconhecimento da Denominação de Origem “Terra Indígena Andirá-Marau”. 2016.

INPI - INSTITUTO NACIONAL DA PROPRIEDADE INDUSTRIAL. Processo Administrativo para o Reconhecimento da Indicação de Procedência “Maués”. 2015.

INPI - INSTITUTO NACIONAL DA PROPRIEDADE INDUSTRIAL. Revista da Propriedade Industrial, Rio de Janeiro, Seção IV, n. 2.454, 16 janeiro 2018. Disponível em: http://revistas.inpi. gov.br/rpi/. Acesso em: 2 jul. 2018.

IPHAN - INSTITUTO DO PATRIMÔNIO HISTÓRICO E ARTÍSTICO NACIONAL. O Iphan. 2019a. Disponível em: http://portal.iphan.gov.br/pagina/detalhes/872. Acesso em: 5 fev. 2019.

IPHAN - INSTITUTO DO PATRIMÔNIO HISTÓRICO E ARTÍSTICO NACIONAL. Perguntas Frequentes sobre CTA. 2019b. Disponível em: http://portal.iphan.gov.br/pagina/detalhes/849/. Acesso em: 5 fev. 2019.

NIEDERLE, P. A.; MASCARENHAS, G. C. C.; WILKINSON, J. Governança e Institucionalização das Indicações Geográficas no Brasil. RESR, Piracicaba, v. 55, n. 1, p. 85-102, jan.-mar. 2017.

OMPI - ORGANIZAÇÃO MUNDIAL DA PROPRIEDADE INTELECTUAL. Conhecimentos tradicionais e propriedade intelectual. Nota informativa, 2016. Disponível em: http://www.wipo. int/edocs/pubdocs/pt/wipo_pub_tk_1.pdf. Acesso em: 28 jun. 2018.

SANTILLI, J. Patrimônio Imaterial e Direitos Intelectuais Coletivos. In: BARROS, B. S. et al. (org.). Proteção aos Conhecimentos das Sociedades Tradicionais. Pará: Museu Paraense Emílio Goeldi, Centro Universitário do Pará. 2007. p. 119-138.

SILVA, A. C. B. et al. Aliança guaraná de maués: a cadeia de valor do guaraná de Maués. Manaus: IDESAM, 2018.

SOUZA, E. S. As práticas tradicionais e a introdução das inovações tecnológicas no cultivo do guaraná (Paullinia cupana var. sorbilis) junto aos produtores de Maués/AM - Brasil. 2016. 66 f. Dissertação (Mestrado em Educação Agrícola) - Universidade Federal Rural do Rio de Janeiro, Seropédica, RJ, 2016.

SOUZA, K.; LOCATELLI, L. Proteção Jurídica dos Conhecimentos Tradicionais pelo Instituto das Indicações Geográficas. Revista de Direito, Inovação, Propriedade Intelectual e Concorrência, Minas Gerais, v. 1, n. 2, p. 42-59, jul.-dez. 2015. 
VALENTE, M. E. R. et al. Indicação Geográfica de alimentos e bebidas no Brasil e na União Europeia. Ciência Rural, Santa Maria, v. 42, n. 3, p. 551-558, mar. 2012. Disponível em: http:// www.scielo.br/pdf/cr/v42n3/a7712cr5407.pdf. Acesso em: 10 jul. 2018.

VALENTE, M. E. R.; PEREZ, R.; FERNANDES, L. R. R. M. V. O processo de reconhecimento das indicações geográficas de alimentos e bebidas brasileiras: regulamento de uso, delimitação da área e diferenciação do produto. Ciência Rural, Santa Maria, v. 43, n. 7, p. 1.330-1.336, jul. 2013. Disponível em: http://www.scielo.br/pdf/cr/v43n7/a18113cr2012-0405.pdf. Acesso em: 10 jul. 2018.

\section{Sobre os autores}

\section{Igor Schumann Seabra Martins}

E-mail: igorschumann@gmail.com

Especialista em Controladoria e Gestão Pública pela Universidade Federal do Rio de Janeiro.

Diretoria de Marcas, Desenhos Industriais e Indicações Geográficas, Instituto Nacional da Propriedade Industrial. Endereço profissional: Rua Mayrink Veiga, n. 9, Centro, Rio de Janeiro, RJ. CEP: 20090-050.

\section{Alexandre Guimarães Vasconcellos}

E-mail: alexguim@inpi.gov.br

Doutor em Biotecnologia Vegetal pela Universidade Federal do Rio de Janeiro.

Endereço profissional: Academia de Propriedade Intelectual, Inovação e Desenvolvimento, Instituto Nacional da Propriedade Industrial, Rua Mayrink Veiga, n. 9, Centro, Rio de Janeiro, RJ. CEP: 20090-050. 